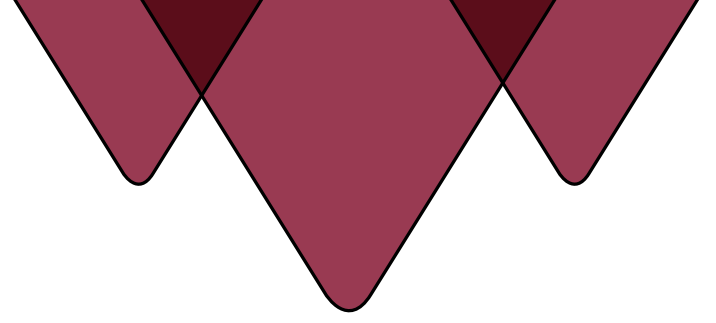

\title{
Shifting Established Mindsets and Praxis in Libraries: Five Insights for Making Non-Western Knowledge Digitally Accessible through Community Engagement
}

\author{
Karim Tharani \\ University of Saskatchewan
}

\begin{abstract}
This paper is a reflection on the challenges encountered and decisions made as part of a multiyear community-based action research project to digitally curate a living oral tradition. At the core of this initiative was an exploration of the ways academic librarians in Canada can leverage existing library services and systems and engage with the community to improve accessibility of non-Western knowledge materials. The author collaborated with several members of the Ismaili community across western Canada to find ways to digitally curate their revered oral tradition of ginans (gnostic and devotional hymns) in a culturally respectful and responsible way. The purpose of this article is to share five insights gained during the course of this exploration: I) value relationships over tasks, 2) accept community engagement as a continuum, 3) learn to appreciate rather than appropriate materials, 4) consider oral sources to be as important as textual ones, and 5) accept community materials as credible knowledge resources.
\end{abstract}

Keywords: digital accessibility · digital curation · ginans · non-Western knowledge · oral traditions

RÉSUMÉ

Cet article est une réflexion sur les défis rencontrés et les décisions prises dans le cadre d'un projet de recherche pluriannuel d'action communautaire visant à conserver numériquement une tradition orale vivante. Au cour de cette initiative se trouvait une exploration des façons dont les bibliothécaires universitaires au Canada peuvent tirer parti des services et des systèmes de bibliothèques existants et collaborer avec la communauté pour améliorer l'accessibilité des documents de savoir non occidentaux. L'auteur a collaboré avec plusieurs membres de la communauté ismaélienne de l'Ouest canadien pour trouver des moyens de conserver numériquement leur vénérée tradition orale de ginans (hymnes gnostiques et dévotionnels) d'une manière culturellement respectueuse et responsable. Le but de cet article est de partager cinq 
perspectives acquises au cours de cette exploration: I) valoriser les relations plutôt que les tâches, 2) accepter l'engagement communautaire comme un continuum, 3) apprendre à apprécier le matériel plutôt que se l'approprier, 4) donner la même importance aux sources orales qu'au matériel textuel, et 5) accepter le matériel communautaire en tant que ressources crédibles de connaissances.

Mots-clés : accessibilité numérique · conservation numérique · connaissances non occidentales $\cdot$ ginans $\cdot$ traditions orales

Academic librarians play a vital role in safeguarding and sharing historical and emerging knowledge. In many ways, Western societies rely on academic librarians to be impartial custodians of past and present knowledge on behalf of the public. In Canada, as in most Western societies, the primary medium to codify knowledge continues to be written text, whether in print or electronic format. Consequently, bibliographic standards and practices in academic libraries have evolved to be very efficient in managing textual knowledge materials and making them accessible. This specialized operational efficiency, however, comes at the cost of marginalizing non-textual, and by extension non-Western, knowledge carriers, including oral traditions. This issue has received renewed attention among academic librarians in Canada as they have taken into consideration the calls to action put forth by the Truth and Reconciliation Commission of Canada to be more inclusive and unbiased toward Indigenous knowledge, cultures, and languages.

How can academic librarians chart a path of rectitude in establishing equality and justice for accessibility of non-Western knowledge? This is a quintessential question that academic librarians need to address. In her book Unsettling the Settler Within: Indian Residential Schools, Truth Telling, and Reconciliation in Canada, Paulette Regan (20IO) recommends that individuals take concrete steps to unsettle established practices that continue to perpetuate a colonial mindset. A way forward for academic librarians, therefore, is to make sincere and sustainable shifts to the prevailing and unchallenged library practices by making conscious and informed operational choices in the interest of the public good.

\section{Literature Review}

Academic librarians continue to struggle with making non-Western knowledge sources and resources widely accessible to patrons (Nakata et al. 2005; Nicolas 2005; Battiste and Henderson 2000). There are a variety of historical and systemic factors that contribute to this impasse, including a lack of education and comfort among librarians as well as the inadequacy of the existing controlled vocabulary to describe materials that are outcomes of intricate non-Western knowledge systems 
and cultures. Individual librarians often perceive these challenges as insurmountable, resulting in systemic neutrality and inaction. Critical librarianship warns against such inaction: "one tenet of critical librarianship is that neutrality is not only unachievable, it is harmful to oppressed groups in our society" (Farkas 2017, 70). Thus, critical librarianship can help academic librarians "confront the institutional and personal biases which are present in academia" (Vangeest and Hawkins 2016, 5). For example, the University of Alberta Libraries formed the Decolonizing Description Working Group (DDWG) to "investigate, define, and propose a plan of action for how we could more accurately, appropriately, and respectfully represent Indigenous peoples and contexts through our descriptive metadata practices" (Farnel et al. $2018,99)$. This approach of coming together as a team is an effective way to dissipate individual apprehensions about handling Indigenous and other non-Western knowledge materials.

In addition to building an internal support group, the DDWG has been deliberate about building respectful working relationships with and reaching out to various Indigenous communities in Alberta for input and direction. This approach of community engagement and relationship-building is crucial, according to Battiste and Henderson, authors of Protecting Indigenous Knowledge and Heritage: A Global Challenge, who regard relationships as the basis of creation and preservation of knowledge in the Indigenous context $(2000,42)$ :

\footnotetext{
Perhaps the closest one can get to describing unity in Indigenous knowledge is that knowledge is the expression of the vibrant relationships between the people, their ecosystems, and the other living beings and spirits that share their lands. These multilayered relationships are the basis for maintaining social, economic, and diplomatic relationships - through sharing - with other peoples.
}

As well as the lack of appropriate representation of Indigenous contexts in subject headings, a lack of clarity on how best to safeguard the sanctity of sacred knowledge also contributes to inaccessibility of non-Western knowledge in academic libraries. Existing access policies in libraries, which were originally put in place for Western knowledge materials, remain simplistic and fail to address the intricacies of sacred knowledge by imposing incompatible and often inappropriate attributions and access rights on such resources. Despite these challenges, Maina $(2012,24)$ urges library professionals to continue to

get more involved in the ongoing traditional knowledge protection debate in order to gain further understanding of indigenous worldviews and pedagogy and establish how traditional knowledge holders understand their knowledge and establish what systems and practices would be helpful in its preservation. 
One of the ways in which academic librarians can get involved is by identifying and leveraging service areas where they have been successful in engaging local communities. For instance, many academic libraries have had digitization and digital repositories since the early I990s and have infrastructure in place to host local digital collections (Marsh et al. 20I6; Lopatin 2006). A primary focus of digital collections in academic libraries is to make unique and rare materials from local communities accessible to academia and beyond (Oestreicher 2015). This presents a real and actionable opportunity for academic librarians to collaborate with communities who are interested in sharing or safeguarding their history and heritage.

Another area of strength for academic librarians is project management. Public institutions, including universities, often use project-management guidelines and templates to advance unique and strategic initiatives (Crawford and Helm 2009). Many organizations undertake projects as a means of learning and easing new services into their operations. Project-management templates and tools are also widely used by academic librarians for their research and scholarly activities. In fact, academic librarians are often part of research projects that involve digitization and curation of unique and rare collections (Lopatin 2006). In working with communities, researchers, including academic librarians, often find themselves taking on project-management responsibilities to facilitate discussions and decisions in order to achieve desired goals. Taking a project-based approach in communitybased initiatives provides an opportunity to collaboratively develop project plans that take into account the scope, budget, timelines, and availability of resources. An additional advantage of a project-based approach is that the objectives and norms that will govern team meetings and decisions need to be negotiated and documented prior to starting the work. Sharing project-management experience and skills with Indigenous and other non-Western community members in exchange for their cultural expertise and knowledge provides an avenue for librarians to forge purposeful partnerships based on reciprocity and mutual respect.

\section{Methodology}

The initiative to digitally curate an oral tradition was a self-initiated quest to explore how librarians can help improve discoverability of non-Western knowledge materials in libraries. The research entailed several years of effort in gathering and categorizing over 500 items of source materials and digitally curating them, using prototyping as the primary research method. The work was scoped into multiple smaller curation projects based on source material types, such as audio recordings, manuscripts and lithographs, or printed publications. These smaller projects, in turn, served as building blocks for an integrated framework for digitally curating a living oral tradition. 
Despite the technological focus of this exploratory research, two methodological approaches were at the forefront during the course of this study: an Indigenous approach to research, and participatory action research. The author embraced as an overall guiding principle an Indigenous approach to research, which recognizes that community-based research does not happen in isolation but rather in the context of a community and its epistemology, knowledges, and traditions. This Indigenous approach to research empowered the author, a member of the Ismaili community, to undertake this research with passion, objectivity, and transparency. As Kovach notes in her seminal book Indigenous Methodologies (2009, 7):

We know what we know from where we stand. We need to be honest about that. I situate myself not as a knowledge-keeper — this has not been my path-rather my role is facilitator, I have a responsibility to help create entry points for Indigenous knowledge to come through.

Some may argue that using an Indigenous approach to research in nonIndigenous contexts may be another form of appropriation, but for the author there is a deep sense of kinship with other non-Western communities in an Indigenous approach to research. As Wilson asserts in a comment on Lee (2OI4),

Indigenism can be generalized to other fields and to diverse researchers who choose this relational way of doing research-just as feminist philosophy can be applied beyond the field of women's studies or by genders other than female.

Despite this sense of kinship among Indigenous and other non-Western communities, it is important to recognize and emphasize that the issues faced by Indigenous communities in Canada remain distinct from those of diaspora and other ethnocultural communities who are not the original occupants of Canada.

At a more practical level, the tenets of participatory action research (PAR) guided the author during interactions with community participants. In PAR, both researchers and participants share power equally, which

eliminates the inequality that traditionally occurs with researchers and participants in a typical research design. All team members participate in making collaborative decisions. Everyone has unique and equally important contributions that create mutual learning. (Watters, Comeau, and Restall 20I0, 5-6)

\section{Curating the Oral Tradition of Ginans of the Ismaili Community}

The Ismaili community ${ }^{\mathrm{I}}$ is culturally diverse and faith-based, living mostly in minority and diaspora settings across the globe. Within the cultural and geographical plurality of the Ismaili community, the oral tradition of ginans pertains to the

I. For more information, see the official website of the Ismaili Muslim community at HT TPs://WWW. THEISMAILI.ORG. 
Ismailis of South Asia, who are popularly known as Khojas. ${ }^{2}$ Ginans continue to play a vital role in the religious life of the Ismaili community. The term ginan literally means sacred knowledge or gnosis and is used in the community to refer to single compositions or hymns from a collection of around I ooo compositions. Originating in the Indian subcontinent as early as the I3th century, the tradition of ginans has been carried forward orally in the community since then (Asani 1992). Over the years, community members have emigrated from India for political, religious, or economic reasons. Thus, in order to mitigate the risk of losing the tradition as members of the community moved away from India to other parts of the world, community leaders and elders started rendering ginans to manuscripts. As a result, the corpus of ginans now includes transliterations and translations of ginans in multiple languages, including English. Asani, however, points out that despite the textual sources and resources that surround this tradition, the community continues to honour the oral and aural dimensions of the ginans (1992, IO4):

The reverence shown to the ginān as written word should not, however, mislead us.

Though they have been embodied in a written textual form, the gināns are primarily an oral tradition. Their greatest impact is through the ear. They are intended to be chanted and recited aloud according to prescribed rāgas (melodies) and folk tunes. Singing ginān, alongside the performance of ritual prayers, is one of the mainstays of the worship service in the mornings and evenings when the community congregates in the jamāat-khāna for prayers. Memorization of at least a few ginans and their tunes constitutes an essential part of the religious education of the Khoja Ismaili children... Nowadays, the oral and memorized text continues to be functionally more important than the written text, which appears more of an aide-mémoire for the man or woman who leads the congregation in recitation.

\section{Shifting Established Mindsets and Practices in Libraries}

As noted before, the initiative to digitally curate an oral tradition for longterm accessibility was undertaken as an exploration of how to collaborate with communities who have a rich heritage of oral traditions, in order to chart out a responsible and respectful way to safeguard their heritage. To this end, the author collaborated with several members of the Ismaili community across western Canada to digitally curate their revered oral tradition of ginans. This community-based initiative resulted in the development of the Ginan Central portal, ${ }^{3}$ which was based on this collaborative approach to digitally curate ginans for posterity and access.

While the research initiative to digitally curate the oral tradition of ginans was undertaken in the specific context of the Ismaili community, the insights gained in the process of this research are relevant and applicable for any academic librarians

2. For more information on this term, see HTTPS://EN.WIKIPEDIA.ORG/WIKI/KHOJA.

3. The Ginan Central portal can be accessed at HTTP://GINANS.USASK.CA. 
who collaborate with Indigenous and other ethnocultural communities in Canada to improve accessibility of non-Western materials in academic libraries. The five insights presented here were informed by the challenges encountered and decisions made as the author worked to leverage existing library services and systems and engage with the community to help raise the status of non-Western knowledge materials in libraries. The purpose here is not to share details of what the work entailed or how this work was done, but rather to share lessons the author has derived through reflecting on the multi-year journey of unlearning and relearning to digitally curate the oral tradition of ginans.

\section{Value Relationships over Tasks}

Academic librarians strive to fulfill their mandate as custodians of past and present knowledge by establishing efficient workflows and tasks. To conform to established performance and assessment criteria, they are inclined to value processes that are predictable, repeatable, and measurable. Under this paradigm, any new and unique initiatives, including community collaborations, are initially taken up as one-off projects that have preordained resources and predetermined start and end dates. Working in and with community, however, time and attention must also be directed toward building relationships rather than just executing tasks that are outlined in project plans. When partnering with non-Western communities, librarians ought to plan for sustaining the relationships that are forged as part of these projects. This is particularly important in Indigenous communities where relationships are layered and expressed through knowledge sharing (Battiste and Henderson 2000).

In the case of the Ismaili community, establishing trust with community elders, leaders, and youth was vital in uncovering and understanding the needs and challenges of the community. Without this trust, for instance, the author would not have been privy to the sentiments of the community youth vis-à-vis the use of digital and web technologies to learn ginans. Uncovering these sentiments helped in identifying potential technology-based learning aids to improve youth engagement in communities that were facing challenges in transmitting oral traditions to successive generations (Tharani 20I5).

\section{Accept Community Engagement as a Continuum}

Communities, much like families, consist of individuals with different personalities, education, and experiences that inform each person's perspective and outlook on life. And even though members of a community may share common historical or theological roots, they are seldom monolithic in their opinions, preferences, or 
decisions. This requires librarians to be attuned to sentiments and sensitivities of the individuals within the community.

While working with members of the Ismaili community, it was clear that there was overall consensus among the community members to safeguard ginans, but when it came to specific issues, the decisions were seldom unanimous. Based on this observation, the author developed the Community Engagement Model that identified four levels of collaboration that community members tended to exhibit when faced with an issue or decision: closed, casual, contingent, or committed (Tharani 20I7). This model, shown in figure I, made it easier to communicate and appreciate why community members may become uncooperative or closed on certain issues.

\section{" Community Engagement Model}

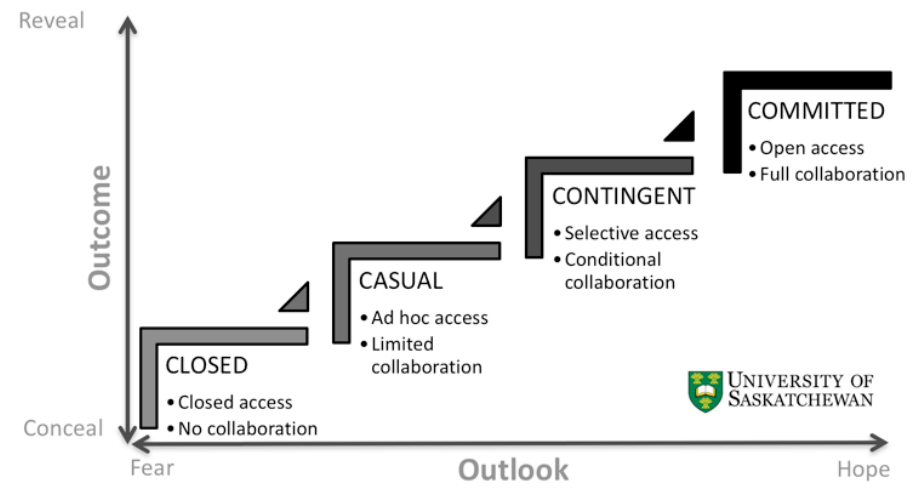

FIGURE I

The Community Engagement Model (Tharani 2017).

For librarians to be productive and successful in their work with non-Western community members, it is crucial that they acknowledge and appreciate these varying sentiments. Taking an objective and realistic approach helps bring clarity to complex community dynamics and find ways to move forward with acceptable and defined boundaries. Moreover, such a humanistic approach also gives community members an opportunity to reflect and reconcile their individual and collective commitment with respect to the agreed-upon project goals and objectives.

\section{Learn to Appreciate Rather than Appropriate Materials}

As part of typical operational workflows in libraries, physical materials are selected, acquired, and described before being made available through library catalogues and other discovery and access systems. These workflows and processes make librarians effective in working with various suppliers and vendors of library materials and metadata records. In the case of accessing knowledge materials embedded in non- 
Western communities, however, these established practices may be of little or no use. In particular, the very notion of acquisition, as practised by librarians, may not be culturally appropriate when working with Indigenous and other ethnocultural communities. In some Indigenous communities, for instance, the practice of requiring collections to be physically shipped away to libraries for processing may still be perceived as continuing the historical process of colonization and appropriation. In order to be trustworthy partners in non-Western communities, it is imperative for librarians to overtly demonstrate an appreciative mindset by exercising flexibility in processing community collections. This may mean adjusting existing workflows or deploying digitization and cataloguing processes in the communities where the materials are physically located.

In the author's prior work on digitizing community collections, the Collections Digitization Framework, shown in figure 2, was specifically designed for academic libraries to mobilize digitization services to communities in order to "create unique opportunities to access and share hidden knowledge embedded within local and remote communities with rich intellectual traditions" (Tharani 2012). Thus, for a community-based collaborative initiative to be productive, librarians need to shift their mindset from one that focuses on physically gathering collections in libraries to one that prioritizes mobilizing processes to off-campus locations.

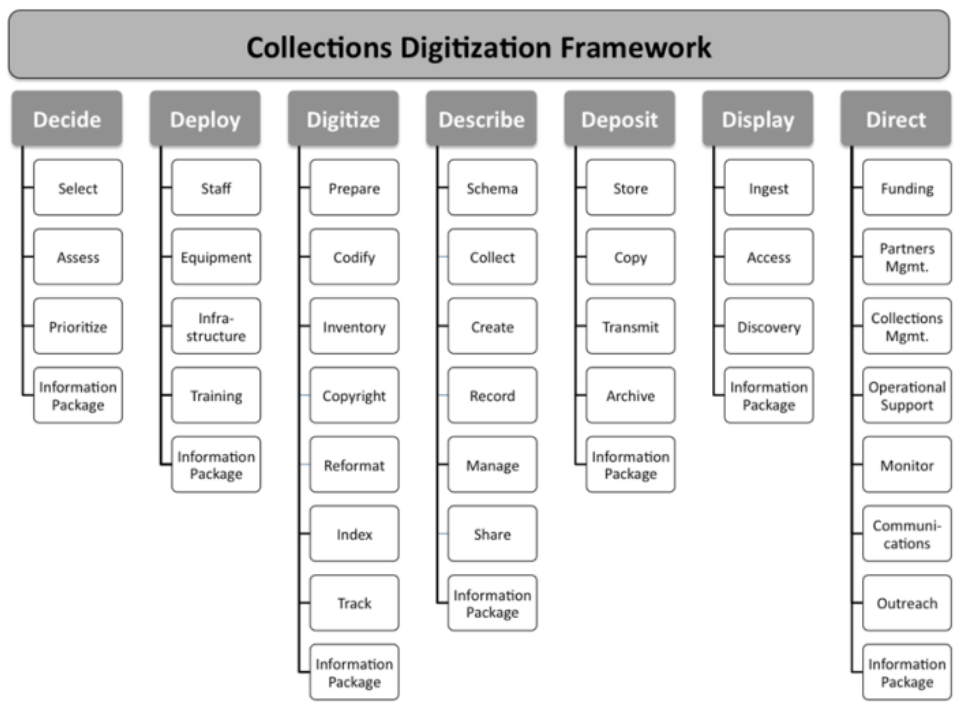

FIGURE 2

The Collections Digitization Framework (Tharani 20I2). 


\section{Consider Oral Sources to Be as Important as Textual Ones}

Current practices of teaching and instruction in Western academia generally perpetuate the primacy of textual sources for acquiring knowledge and literacy. While digital and web technologies have become essential for Western pedagogy, they continue to be used as vehicles to overcome geographical and temporal barriers in access rather than to displace the primacy of textual materials. Consequently, academic librarians are accustomed to working with tangible, textbased knowledge carriers, whether in print or electronic format. In non-Western communities, however, the orality of knowledge continues to be alive and grounded in epistemological conviction rather than physical convenience.

Oral traditions by their very definition and nature are alive and current, but there is a tendency in Western academia to regard them as static or historical knowledge. Academic librarians working with Indigenous and other ethnocultural communities ought to correct their erroneous mindset which "equates Indigenous knowledge to "past' knowledge, when in fact Indigenous people view their knowledge as continuing" (Nakata et al. 2005, 9). The oral tradition of ginans continues to be a living tradition in the Ismaili community, where

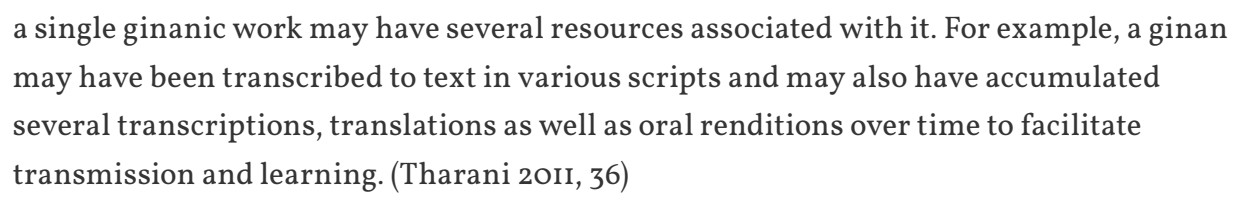

These communal resources are created by community elders and educators to complement traditional teaching and transmission methods.

\section{Accept Community Materials as Credible Knowledge Resources}

Rendering oral traditions to text eliminates the richness that is conveyed through sound. Despite such loss of richness, prevailing Western scholarly norms prefer reducing oral traditions to textual renditions for research and scholarly attention. Historically, the only way for oral traditions to be accepted in academia as credible sources for research and education was through textual criticism, a process devoted to identifying reliable texts of ancient and oral knowledge that had been committed to manuscripts (Tanselle I990). While developing critical editions may have worked well for scriptures with established authorships, this remains a questionable practice for oral traditions. In the context of ginans, for instance, Asani (I996, 276) asserts that "the application of conventional canons of textual criticism involving the tracing of transmission line to an ideal archetype or autograph is futile and inappropriate."

As discussed before, elders and educators in many communities choose to render oral traditions to text and other media to complement (rather than to 
replace) their traditional ways of teaching and transmitting oral knowledge. In the Ismaili community as well, members of the community have produced a variety of communal editions of romanized or English texts of ginans to help teach and transmit ginans to younger generations, particularly those living in North America and Europe. These romanized communal editions of ginans have not only served the liturgical needs of the community but have also helped make ginans more accessible and comprehensible to younger generations of the community born and raised in diasporas. Since these resources are seldom included in scholarly discourses, academic librarians have a unique opportunity to make such communal materials accessible in academia for research and pedagogy.

\section{Conclusion}

Academic librarians have first-hand experience of how biased control over public knowledge can be detrimental to the quality of knowledge in academia and society. Exactly two decades ago, Google made its debut as a commercial search engine to help people find information on the web. While this was a much-welcomed information service for the web, it did not take long for Google to evolve its commercial interests and business model from being a facilitator of public information to becoming a controller of public knowledge. Few members of the public today pause to wonder why searching for a book using Google's search engine never leads them to a library. Even more disconcerting is the fact that the rules and algorithms used by Google to share or suppress information on the web remain obscure and proprietary.

Unlike Google, however, the existing bias towards written texts in academic libraries is neither deliberate nor covert, but a byproduct of historical and operational choices. As impartial and fair stewards of past and present knowledge, academic librarians have an important and active role to play in making unique and rare community-knowledge traditions and materials accessible to Canadians. This means that, even though the prevailing mindset in libraries is one of efficiency, it is crucial for academic librarians to carve out time and resources to learn from community members in order to gain knowledge, skills, and confidence in making non-Western knowledges more accessible in academia and beyond.

The calls to action from the Truth and Reconciliation Commission of Canada serve as a striking reminder that the established practices that have put Indigenous knowledge at a disadvantage in academic libraries will not be unsettled by wishful thinking alone. It will require courage, curiosity, creativity, and, above all else, thoughtful and decisive actions by academic librarians working with non-Western communities to appreciate different ways of learning, working, and sharing knowledge. The author hopes that the insights shared in this article will 
help academic librarians do their part to make non-Western knowledge materials increasingly accessible.

\section{ABOUT THE AUTHOR}

Karim Tharani is an information technology librarian and currently serves as Head of Library Systems and Information Technology at the University of Saskatchewan Library. His research interests include digital access and preservation, digital curation of oral traditions, database and Linked Data technologies, digital humanities, and the use of information technology in community and interdisciplinary contexts.

\section{REFERENCES}

Asani, Ali S. 1992. "The Ismaili Ginans as Devotional Literature." In Devotional Literature in South Asia: Current Research, 1985-1988: Papers of the Fourth Conference on Devotional Literature in New Indo-Aryan Languages, held at Wolfson College, Cambridge, I-4 September 1988, edited by Ronald Stuart McGregor, IOI-I2. Cambridge: Cambridge University Press.

. 1996. "The Isma'ili Ginans: Reflections on Authority and Authorship." In Mediaeval Isma'ili History and Thought, edited by Farhad Daftary, 265-80. Cambridge: Cambridge University Press.

Battiste, Marie, and James Youngblood Henderson. 200o. Protecting Indigenous Knowledge and Heritage: A Global Challenge. Saskatoon, SK: Purich.

Crawford, Lynn H., and Jane Helm. 2009. "Government and Governance: The Value of Project Management in the Public Sector.” Project Management Journal 4O (I): 73-87. H T T P S://DOI.ORG/IO.IO O $2 /$ PMJ.2OIO7

Farkas, Meredith. 20I7. "Never Neutral: Critical Librarianship and Technology." American Libraries 48 (I/2): 70 .

Farnel, Sharon, Denise Koufogiannakis, Ian Bigelow, Anne Carr-Wiggin, Debbie Feisst, Kayla Lar-Son, and Sheila Laroque. 20I8. "Unsettling Our Practices: Decolonizing Description at the University of Alberta Libraries." International Journal of Information, Diversity, \& Inclusion 2 (I/2). H T T P S://PU B LIS H. LIB. UMD.EDU/IJIDI/ARTICLE/VIEW/424

Kovach, Margaret. 2009. Indigenous Methodologies: Characteristics, Conversations, and Contexts. Toronto: University of Toronto Press.

Lee, Che-Wei. 20I4. "What is an indigenous research paradigm? Can this paradigm be generalized to other fields? How can diverse researchers engage and benefit from it?" ResearchGate (discussion question). HTTPS://WWW.RESEARCHGATE.NET/POST/WHAT_ _ IS _ AN _ INDIGENOUS _ RESEARCH _ PARADIGM _ CAN _ THIS _ PARADIGM _ BE_ GENERALIZED _ TO _ OTHER _ FIELDS _ HOW _ CAN _ DIVERSE _ RESEARCHERS _ ENGAGE _ AND _ BENEFIT _ FROM _ IT

Lopatin, Laurie. 2006. “Library Digitization Projects, Issues and Guidelines: A Survey of the Literature." Library Hi Tech 24 (2): 273-89. HT P S://DOI.ORG/IO.IIO8/073788306IO669637

Maina, Charles Kamau. 2012. "Traditional Knowledge Management and Preservation: Intersections with Library and Information Science." International Information \& Library Review 44 (I): I3-27. HTT Ps:// DOI.ORG/IO.IO80/IO5723I7.20I2.IO7629II

Marsh, Diana E., Ricardo L. Punzalan, Robert Leopold, Brian Butler, and Massimo Petrozzi. 2016. "Stories of Impact: The Role of Narrative in Understanding the Value and Impact of Digital Collections." Archival Science I6 (4): 327-72. HT T s://DoI.orG/IO.IOO 7/sIO5O2-015-9253-5

Nakata, Martin, Alex Byrne, Vicky Nakata, and Gabrielle Gardiner. 2005. "Indigenous Knowledge, the Library and Information Service Sector, and Protocols." Australian Academic \& Research Libraries 36 (2): 7-2I. HTTPS://DOI.ORG/IO.IO80/OOO48623.2005.IO72I 244

Nicolas, Yann. 2005. "Folklore Requirements for Bibliographic Records: Oral Traditions and FRBR." Cataloging \& Classification Quarterly 39(3-4): I79-95. HTTPS://DOI.ORG/IO.I300/JIO4V39NO3_ II 
Oestreicher, Cheryl, ed. 2015. Innovation, Collaboration, and Models: Proceedings of the CLIR Cataloging Hidden Special Collections and Archives Symposium. Washington, DC: Council on Library and Information Resources. HTtPS://FILES.ERIC.ED.GOV/FULLTEXT/ED56I290.PDF

Regan, Paulette. 20I0. Unsettling the Settler Within: Indian Residential Schools, Truth Telling, and Reconciliation in Canada. Vancouver: UBC Press.

Tanselle, G. Thomas. 1990. “Textual Criticism and Deconstruction." Studies in Bibliography 43: I-33. HTTP://WWW.JSTOR.ORG/STABLE/4O37I9I9

Tharani, Karim. 20II. "From Abstraction to Action: Safeguarding Oral Traditions Using Digital Libraries." International Journal of Religion and Spirituality in Society I (2): 33-46. H T T P s://D I. ORG/IO.I8848/2I54-8633/CGP/VOIIO2/5II4O

. 2012. "Collections Digitization Framework: A Service-Oriented Approach to Digitization in Academic Libraries." Partnership: The Canadian Journal of Library and Information Practice and Research 7 (2): I-I3. HTTPS://DOI.ORG/IO.2IO83/PARTNERSHIP.V7I2.2OIO

- 2015. "Wanted: The Five Most Sought-After Educational Apps to Enhance Learning of Oral Traditions in a Digital Age." In Proceedings of EdMedia 2015-World Conference on Educational Media and Technology, edited by S. Carliner, C. Fulford, and N. Ostashewski, I537-545. Waynesville, NC: Association for the Advancement of Computing in Education. HTTPS://WWW.LEARNTECHLIB.ORG/ PRIMARY/P/I5I532/

. 2017. "Sound Approach: Digital Curation of Oral Traditions for Access and Preservation." In Proceedings of the 2nd International Ismaili Studies Conference "Mapping a Pluralist Space in Ismaili Studies," edited by Karim H. Karim, 72-76. Ottawa, ON: Carleton Centre for the Study of Islam, Carleton University. HTTPS://CARLETON.CA/ISLAMSTUDIES/WP-CONTENT/UPLOADS/PROCEEDINGS-OF-ISC 2 OI 7. PDF

Vangeest, Jacob, and Blake Hawkins. 20I6. "How To Be a \#critlib: Reflections on Implementing Critical Theory in Practice." See Also 2 (I). HTtps://ojs.LibRARy.ubc.CA/IndeX.Php/SEeAlso/ARticle/ VIEW/I 87907

Watters, Julie, Savanna Comeau, and Gayle Restall. 20I0. Participatory Action Research: An Educational Tool for Citizen-Users of Community Mental Health Services. University of Manitoba. Hт TP://Um A NitoBA.CA/ MEDREHAB/MEDIA/PAR _ MANUAL.PDF 